\title{
Cultures of Participation and Social Computing: Rethinking and Reinventing Learning and Education
}

\author{
Gerhard Fischer \\ Center for LifeLong Learning \& Design (L3D) \\ University of Colorado, Boulder, CO, USA \\ gerhard@,colorado.edu
}

\begin{abstract}
:
The rise in social computing (based on social production and mass collaboration) has facilitated a shift from consumer cultures grounded in an industrialized information economy (specialized in producing finished goods to be consumed passively) to cultures of participation in a networked information economy (in which all people are provided with the means to participate actively in personally meaningful problems). These developments represent unique and fundamental opportunities and challenges for rethinking and reinventing learning and education. Our research in the Center for LifeLong Learning \& Design (L3D) explores theoretical foundations such as meta-design and social creativity and designs, develops, and assesses sociotechnical environments for this transformation.
\end{abstract}

\section{Introduction}

Media and technologies can and should serve as extensions of humans [McLuhan, 1964]. The history of the human race is one of ever-increasing intellectual capability: our brains have gotten no bigger and our hands no more skilled or stronger, but there has been a continuous accumulation of new tools for physical and intellectual work.

I have argued before that many advanced learning technology approaches are too timid and are not thinking radically enough for the following reasons [Fischer, 2007]:

- accepting too many established approaches- - .g.: a theory of human learning based solely on school learning is too limited but the success of universal schooling has led us to identify learning with schooling [Collins \& Halverson, 2009; Illich, 1971];

- not embracing new learning opportunities-e.g.: exploiting the unique opportunities of social production in which all learners can act as active contributors in personally meaningful problems [Fischer, 2002];

- reducing digital literacy and fluency to accessing and comprehending existing information rather than empowering learners to reformulate knowledge, to express themselves creatively and appropriately, and to produce and generate information [Brown \& Adler, 2008]; and

- not moving beyond "gift-wrapping" and "technodeterminism" to the co-evolution of learning, new media, and new learning organizations [Fischer, 1998].

\section{Problems and Fundamental Transformations}

Learning and education are experiencing a period of profound transformation. Phenomena such as globalization, increasing trends to outsource high-level cognitive tasks, and the need to participate effectively in addressing complex world problems are changing how we think, learn, work, and collaborate. New knowledge and skills for students to enter work environments require collaboration with experts from multiple fields, the pursuit of several career paths, and interacting and working with people of diverse backgrounds. Such changes create new educational demands: students need to be educated for a diverse, technical, problem-oriented world that does not yet exist. It is therefore imperative that students become self-directed, lifelong learners who can thrive and participate in collaborative environments with ever-changing disciplinary boundaries. 
Table 1: Fundamental Transformations

\begin{tabular}{|c|c|c|}
\hline dimension & $\begin{array}{l}\text { old paradigm: industrial-age } \\
\text { learning }\end{array}$ & $\begin{array}{l}\text { new paradigm: knowledge-age } \\
\text { learning }\end{array}$ \\
\hline information & scarce & plentiful \\
\hline reproduction of documents & expensive and restricted & inexpensive \\
\hline specialization & low & high \\
\hline change within a human life time & slow (fixed, single career) & fast (multiple careers) \\
\hline interaction / collaboration & physical proximity & shared professional interests \\
\hline economy & rigid, hierarchical organizations & $\begin{array}{l}\text { dynamic economy, flexibility, } \\
\text { networking }\end{array}$ \\
\hline identity formation & long-term personal identity & no long-term \\
\hline participation & $\begin{array}{l}\text { consumers and producers strictly } \\
\text { separated }\end{array}$ & prosumers \\
\hline nature of problems & $\begin{array}{l}\text { problems solved by one } \\
\text { discipline }\end{array}$ & $\begin{array}{l}\text { systemic problems framed and } \\
\text { solved by transdisciplinary } \\
\text { collaboration }\end{array}$ \\
\hline
\end{tabular}

From Schooling to Lifelong Learning. Learning can no longer be dichotomized into a place and time to acquire knowledge (school) and a place and time to apply knowledge (the workplace). The research in our Center for LifeLong Learning \& Design has been grounded in the exploration of the basic assumption: "If the world of working and living relies on collaboration, creativity, definition, and framing of problems, and if it requires dealing with uncertainty, change, and intelligence that is distributed across cultures, disciplines, and tools - then education should foster transdisciplinary competencies that prepare students for having meaningful and productive lives in such a world."

Systemic Problems: The Need for Transdisciplinary Education and Collaboration. Most of the pressing and important problems of today's world are systemic problems that make collaboration supported by new technologies not a luxury but a necessity. These systemic problems (including environmental degradation, economic disparity, and the disappearance of local cultures in the age of globalization, to name just a few) are complex and ill-defined [Simon, 1996], requiring (a) the integration of problem framing and problem solving; (b) communication and collaboration among people from different disciplines and educational levels; and (c) intelligent use of technologies and resources that support collective knowledge construction and extend human problem-solving capability. Learners need to develop new learning skills (such as learning to learn, self-directed learning, learning on demand, and collaborative learning) rather than merely acquiring more information. Table 1 summarizes some of the fundamental transformations to be taken into account in envisioning and creating new advanced learning technologies.

\section{Cultures of Participation and Social Computing}

Cultures of Participation. The first decade of the World Wide Web enforced a clear separation between designers and consumers, but now new technological developments, such as the cyberinfrastructure and Web 2.0 architectures, have emerged to support a social or participatory Web. These developments are the foundations for a fundamental shift from a consumer culture (in which people passively consume finished goods produced by others) to a culture of participation (in which all people are provided with the means to participate actively in personally meaningful activities). Innovative technological developments are necessary for cultures of participation, but they are not sufficient. The deep and enduring changes are not just technological, but social and cultural as well, so socio-technical systems are necessary. Cultures of participation are not dictated by technology - they are the result of incremental shifts in human behavior and social organizations, including design, adoption, appropriation, and adaptation of technologies to the needs of the participants.

Social Computing: 2.0 Everywhere. The 2.0 paradigm (fostering and supporting social production and mass engagement and collaboration) has been spreading to all areas of human activity:

- Web 2.0-User-generated content provided by participants worldwide dominates new information 
environments in all areas [O'Reilly, 2006], including open source software (such as Linux), encyclopedias (such as Wikipedia), photo and movie sharing sites (such as Flickr and YouTube), 3D models (such as the 3D Warehouse), and social networking sites (such as Facebook).

- Learning 2.0-New models of learningintegrating formal and informal learning-are focused on communities of learners engaged in collaborative knowledge construction rather than one-sided processes in which only teachers are responsible for instructionist learning [Brown \& Adler, 2008].

- Science 2.0-The expansion of traditional scientific methods must deal with complex issues that arise as social systems meet technological innovation. This expansion is driven by exploiting the possibilities of the networked information society [Shneiderman, 2008].

- Electricity 2.0-This development applies the lessons of the Web to improve our energy network by arguing that power distribution has been a topdown, subscribe-only model, but the electricity grids of tomorrow will greatly benefit from informed users taking an active part in using the smart grid for saving energy.

- Cognitive-Levers 2.0-In one of our research efforts, we have developed socio-technical environments for people with cognitive disabilities in which caregivers (parents, assistive technology teachers) are empowered to engage in cultures of participation to share information and modify and evolve systems to fit the unique needs of members of this special population [Carmien \& Fischer, 2008].

- President 2.0-This reconceptualization transforms government from a system in which officials hand down laws and provide services to citizens to one that uses the Internet to let citizens, corporations, and civil organizations work together with elected officials to develop solutions.

\section{Emerging Conceptual Frameworks}

We are exploring numerous themes in our efforts to understand, foster, and support cultures of participation with social computing, including the following:

- Models of community [Fischer, 2001], how shared knowledge and common ground are created to support mutual learning and collaborative problem solving;

- Distributed intelligence [Salomon, 1993], the idea that intelligence is not located in a single mind but is distributed among people and tools that work together, and emerges in the process of problem solving;

- Reflection, helping individuals and communities intelligently monitor, assess, and adapt their work through such processes as "reflection-in-action" and "reflection-on-action" [Schön, 1983].

- Lifelong learning [Gardner, 1991], representing a fundamental reconceptualization in which education becomes an integral part of working and living rather than taking place primarily in schools;

- Socio-technical design [Mumford, 2000], the evolutionary creation of effective learning and problem-solving environments made possible with new media and having interacting social and technical components; and

- Exploiting knowledge sources from the "Long Tail" [Anderson, 2006], engaging learners in self-directed learning activities about which they feel passionate.

\section{Foundations for Advanced Learning Technologies}

Inspirational Challenges. Our educational efforts are based on the following prescriptive objectives and empirical observations:

- "The experience of having participated in a problem makes a difference to those who are affected by the solution. People are more likely to like a solution if they have been involved in its generation; even though it might not make sense otherwise" [Rittel, 1984].

- "I believe passionately in the idea that people should design buildings for themselves. In other words, not only that they should be involved in the buildings that are for them but that they should actually help design them" [Alexander, 1984].

- "Users that innovate can develop exactly what they want, rather than relying on manufacturers to act as their (often very imperfect) agents" [von Hippel, 2005].

- "In the digital world, many of the distinctions between designers and users are becoming blurred. We are all, to some extent, designers now" [Brown \& Duguid, 2000].

- "The networked environment makes possible a new modality of organizing production: radically decentralized, collaborative, and nonproprietary" [Benkler, 2006].

- "The opportunity to generate vibrant customer ecosystems where users help advance, implement, and even market new product features represents a largely untapped frontier for farsighted companies to exploit" [Tapscott \& Williams, 2006]. 
The technological foundations to make these objectives a reality are provided by a powerful infrastructure for collaborative efforts (the Internet allows people to share their efforts) and by the increased digital fluency of the population in general, which will make owners of problems independent of "high-tech scribes" in personally meaningful tasks [Fischer, 2002]. Emerging success models, such as open source software and Wikipedia, have provided evidence of the great potential of socio-technical environments in which users can be active contributors.

Meta-Design. Meta-Design [Fischer \& Giaccardi, 2006] is focused on "design for designers." Metadesigners create the social and technical prerequisites for cultures of participation by sharing control over the design process among all stakeholders. Users are empowered with opportunities, tools, and social rewards to extend a system to fit their needs, rather than being forced to use closed systems designed beforehand by software engineers. As owners of problems, users can be active contributors engaged in creating knowledge rather than passive consumers restricted to the consumption of existing knowledge. Meta-design (1) supports a discourse focused on problem domains and not just the computer domain; (2) creates artifacts that can be subjected to critical reflection, open to adjustment and tweaking; (3) supports unintended and subversive uses (not just anticipated ones); and (4) allows learners to engage in personally meaningful activities.

Social Creativity. Social Creativity [Fischer, 2007] is based on the assumption that the power of the unaided individual mind is fundamentally limited. Although creative individuals are often thought of as working in isolation, much human creativity arises from activities that take place in a social context in which interaction with other people and the artifacts that embody collective knowledge are important contributors to the process. The fundamental problems of the $21^{\text {st }}$ century are complex and open-ended, requiring ongoing contributions of many minds, particularly from the people who "own" problems and are directly affected by them. Over the last decade, we have (1) developed sociotechnical environments such as the Envisionment and Discovery Collaboratory [Arias et al., 2001], focused on collaborative problem solving and decision making and supported by table-top computing systems; (2) designed the CreativeIT Wiki to support the research community in "Creativity and IT"; and (3) collaborated with Google in analyzing the $3 D$ Warehouse (one component of interconnected tools that include SketchUp and Google Earth), which stores user-generated 3D models of buildings (and other artifacts) contributed from participants distributed all over the world. We have studied different aspects of these cultures of participation, including motivation to contribute, learning requirements to become a contributor, the role of curators to organize the emerging large space of models, and rating mechanisms for identifying the quality of models.

Long Tail. Information technologies have greatly enhanced the ability to take advantage of the "Long Tail" [Anderson, 2006] by exploiting niche markets and connecting people with communities and products of interest. Schools, however, have moved in the opposite direction. Even as computers become more ubiquitous in schools, curriculum standards and mandated assessments have exercised a conservative force against the proliferation of idiosyncratic interests and passion by emphasizing that everyone should learn the same thing at the same time, as measured by the same standards [Hirsch, 1996]. Similarly, the education establishment has tried to control what people learn by defining the curriculum in schools.

Drawbacks of Cultures of Participation. Cultures of participation open up unique new opportunities for mass collaboration and social production, but they are not without drawbacks. One such drawback is that humans may be forced to cope with the burden of being active contributors in personally irrelevant activities, as illustrated by "do-it-yourself societies." Through modern tools, humans are empowered to perform many tasks themselves that were done previously by skilled domain workers serving as agents and intermediaries. Although this shift provides power, freedom, and control to customers, it also has forced people to act as contributors in contexts for which they lack the experience and interest.

\section{Acknowledgments}

The author thanks the members of the Center for LifeLong Learning \& Design at the University of Colorado, who have made major contributions to the ideas described in this paper. The research was supported in part by (1) grants from the National Science Foundation, including: (a) IIS-0613638 “A Meta-Design Framework for Participative Software Systems, ” (b) IIS0709304 "A New Generation Wiki for Supporting a Research Community in 'Creativity and IT'” and (c) IIS0843720 "Increasing Participation and Sustaining a Research Community in 'Creativity and IT'”; (2) a Google research award, "Motivating and Empowering Users to Become Active Contributors: Supporting the Learning of High-Functionality Environments"; and (3) a SAP research project, "Giving All Stakeholders a Voice: Understanding and Supporting the Creativity and Innovation of Communities Using and Evolving Software Products." 


\section{References}

Alexander, C. (1984) "The State of the Art in Design Methods." In N. Cross (Ed.), Developments in Design Methodology, John Wiley \& Sons, New York, pp. 309-316.

Anderson, C. (2006) The Long Tail: Why the Future of Business Is Selling Less of More, Hyperion, New York.

Arias, E. G., Eden, H., Fischer, G., Gorman, A., \& Scharff, E. (2001) "Transcending the Individual Human Mind-Creating Shared Understanding through Collaborative Design." In J. M. Carroll (Ed.), Human-Computer Interaction in the New Millennium, ACM Press, New York, pp. 347-372.

Benkler, Y. (2006) The Wealth of Networks: How Social Production Transforms Markets and Freedom, Yale University Press, New Haven, CT.

Brown, J. S., \& Adler, R. P. (2008) Minds of Fire: Open Education, the Long Tail, and Learning 2.0, available at http://www.educause.edu/ir/library/ pdf/ERM0811.pdf.

Brown, J. S., \& Duguid, P. (2000) The Social Life of Information, Harvard Business School Press, Boston, MA.

Carmien, S. P., \& Fischer, G. (2008) "Design, Adoption, and Assessment of a Socio-Technical Environment Supporting Independence for Persons with Cognitive Disabilities." In Proceedings of CHI 2008, ACM, Florence, Italy, pp. $597-607$.

Collins, A., \& Halverson, R. (2009) Rethinking Education in the Age of Technology: The Digital Revolution and the School, Teachers College Press, New York (in press).

Fischer, G. (1998) "Making Learning a Part of LifeBeyond the 'Gift-Wrapping' Approach of Technology." In P. Alheit, \& E. Kammler (Eds.), Lifelong Learning and Its Impact on Social and Regional Development, Donat Verlag, Bremen, pp. 435-462.

Fischer, G. (2001) "Communities of Interest: Learning through the Interaction of Multiple Knowledge Systems," 24th Annual Information Systems Research Seminar In Scandinavia (IRIS'24), Ulvik, Norway, pp. 1-14.

Fischer, G. (2002) "Beyond 'Couch Potatoes': From Consumers to Designers and Active Contributors." In Firstmonday (Peer-Reviewed Journal on the Internet), available at http://firstmonday.org/issues/issue 7 12/fischer/.

Fischer, G. (2007) "Designing Socio-Technical Environments in Support of Meta-Design and Social Creativity." In Proceedings of the
Conference on Computer Supported Collaborative Learning (CSCL '2007), Rutgers University, New Brunswick, NJ, July, pp. 1-10.

Fischer, G., \& Giaccardi, E. (2006) "Meta-Design: A Framework for the Future of End User Development." In H. Lieberman, F. Paternò, \& V. Wulf (Eds.), End User Development, Kluwer Academic Publishers, Dordrecht, The Netherlands, pp. 427-457.

Gardner, H. (1991) The Unschooled Mind, Basic Books, New York.

Hirsch, E. D. (1996) The Schools We Need and Why We Don't Have Them, Doubleday, New York.

Illich, I. (1971) Deschooling Society, Harper and Row, New York.

McLuhan, M. (1964) Understanding Media: The Extensions of Man, The MIT Press, Cambridge, MA.

Mumford, E. (2000) "A Socio-Technical Approach to Systems Design," Requirements Engineering, pp. 59-77.

O'Reilly, T. (2006) What Is Web 2.0 - Design Patterns and Business Models for the Next Generation of Software, available at http://www.oreillynet.com/pub/a/oreilly/tim/news/ 2005/09/30/what-is-web-20.html.

Rittel, H. (1984) "Second-Generation Design Methods." In N. Cross (Ed.), Developments in Design Methodology, John Wiley \& Sons, New York, pp. 317-327.

Salomon, G. (1993) Distributed Cognitions: Psychological and Educational Considerations, Cambridge University Press, Cambridge, UK.

Schön, D. A. (1983) The Reflective Practitioner: How Professionals Think in Action, Basic Books, New York.

Shneiderman, B. (2008) "Science 2.0," Science, 319 (March), pp. 1349-1350.

Simon, H. A. (1996) The Sciences of the Artificial, 3rd ed., The MIT Press, Cambridge, MA.

Tapscott, D., \& Williams, A. D. (2006) Wikinomics: How Mass Collaboration Changes Everything, Portofolio, Penguin Group, New York.

von Hippel, E. (2005) Democratizing Innovation, The MIT Press, Cambridge, MA. 